\title{
Enhanced internal gravity wave activity and breaking over the northeastern Pacific-eastern Asian region
}

\author{
P. Š́cha ${ }^{1}$, A. Kuchař ${ }^{1}$, C. Jacobi ${ }^{2}$, and P. Pišoft ${ }^{1}$ \\ ${ }^{1}$ Department of Atmospheric Physics, Faculty of Mathematics and Physics, Charles University in Prague, V Holesovickach 2, \\ Prague 180 00, Czech Republic \\ ${ }^{2}$ University of Leipzig, Institute of Meteorology, Stephanstr. 3, 04103 Leipzig, Germany \\ Correspondence to: P. Šácha (petr.sacha@mff.cuni.cz)
}

Received: 12 March 2015 - Published in Atmos. Chem. Phys. Discuss.: 7 July 2015

Revised: 28 October 2015 - Accepted: 10 November 2015 - Published: 26 November 2015

\begin{abstract}
We have found a stratospheric area of anomalously low annual cycle amplitude and specific dynamics in the stratosphere over the northeastern Pacific-eastern Asia coastal region. Using GPS radio occultation density profiles from the Formosat Satellite Mission 3/Constellation Observing System for Meteorology, Ionosphere, and Climate (FORMOSAT-3/COSMIC), we have discovered an internal gravity wave (IGW) activity and breaking hotspot in this region. Conditions supporting orographic wave sourcing and propagation were found. Other possible sources of wave activity in this region are listed.

The reasons why this particular IGW activity hotspot was not discovered before as well as why the specific dynamics of this region have not been pointed out are discussed together with the weaknesses of using the mean potential energy as a wave activity proxy. Possible consequences of the specific dynamics in this region on the middle atmospheric dynamics and transport are outlined.
\end{abstract}

\section{Introduction}

In the atmosphere, internal gravity waves (IGWs) are a naturally occurring and ubiquitous, despite the fact that intermittent (in the sense of larger amplitude wave packets, e.g. Hertzog et al., 2012; Wright et al., 2013) phenomena influencing its thermal and dynamical structure such as its angular momentum distribution. In particular, IGWs are vitally important in our understanding of the middle and upper atmosphere dynamics as reviewed comprehensively by Fritts and Alexander (2003). In recent years, the significance of
IGWs has been particularly recognised. For example, Ern et al. (2014) pointed out their role in the formation of the quasi-biennial oscillation (QBO) that, together with the findings of Marshall and Scaife (2009), can link them to the European winter surface climate. Ern et al. (2011) suggested that IGWs strongly interact with the polar night jets not only in the mesosphere, but also in the stratosphere. Due to the coupling between the stratosphere and troposphere (Hartley et al., 1998; Haynes et al., 1991), the indirect effect, in this specific case or generally, on surface conditions is unsurprising (Hardiman and Haynes, 2008; Haynes, 2005).

IGWs can also have a direct influence on the middle atmospheric climate change and possibly on the acceleration of the Brewer-Dobson circulation (e.g. Garcia and Randel, 2008). Recently, Demirhan Bari et al. (2013) provided evidence of the effects of IGW activity on the 3-D residual transport in the middle atmosphere.

A number of observational studies have examined the climatological structure of the IGW characteristics using radio occultation (RO) data from Challenging Minisatellite Payload (CHAMP) (e.g. Tsuda et al., 2000; Schmidt et al., 2008), Formosat Satellite Mission 3 - Constellation Observing System for Meteorology, Ionosphere, and Climate (FORMOSAT-3-COSMIC; e.g. Alexander et al., 2009; Horinouchi and Tsuda, 2009; Wang and Alexander, 2009) or using High Resolution Dynamics Limb Sounder (HIRDLS; e.g. Ern and Preusse, 2012) or Sounding of the Atmosphere using Broadband Emission Radiometry (SABER)/Thermosphere Ionosphere Mesosphere Energetics Dynamics (TIMED) satellite data (e.g. Zhang et al., 2012). But, as noted by Wang and Alexander (2010), despite significant advances in our un- 
derstanding of IGWs and their effects in different regions of the atmosphere in the past few decades, observational constraints on their parameters are still sorely lacking, especially for momentum fluxes and IGW propagation direction.

Our paper is focussed on an analysis of the IGW activity in the lower stratospheric region bounded roughly by a tilted ellipse with end points near $30^{\circ} \mathrm{N} 120^{\circ} \mathrm{E}$ and $60^{\circ} \mathrm{N} 180^{\circ} \mathrm{E}$. As we will show in this paper, this area is often a part of a larger region of enhanced IGW activity or breaking, or anomalies of some fields (ozone, wind) that, however, also may reach slightly beyond this region, which is a consequence of largescale dynamical processes. Therefore, in the following our region of interest is roughly defined as this region, but we would refrain from presenting rigid boundaries. The paper is structured as follows: the remainder of the Introduction provides a list of results of observational studies of the IGW activity or characteristics relevant to the region of interest. Description of data and methodology used for processing of the GPS RO data are provided in the next section. The following section (Results) starts with an introduction of climatology of the stratospheric low annual cycle area and then, primarily, results of the analysis of IGW activity and stability in the region of interest are presented. The Results section smoothly passes into the Discussion section (Sect. 3.4), where the results of the wind direction and its change analysis are presented together with discussion of possible wave sources. Possible reasons why this IGW hotspot area was not discovered before are discussed in the Discussion section together with the appropriateness of $E_{\mathrm{p}}$ as a wave activity proxy and with possible implications for the middle atmospheric dynamics (longitudinal variability of BrewerDobson circulation, creation of planetary waves with effects on the polar vortex stability and stratosphere-troposphere exchange). The summary and conclusions are presented in the last section.

\section{Satellite studies of wave activity}

There have been a number of studies that dealt with IGW activity globally. In the following we will give a brief summary of the results bearing some information on the IGW activity, characteristics and peculiarities over our region of interest. Alexander et al. (2008) using 2006/2007 northern hemispheric winter data from FORMOSAT-3/COSMIC found that the potential energy, $E_{\mathrm{p}}$, of IGWs (vertical wavelength $<7 \mathrm{~km}$ ) is mostly related to the subtropical jet stream with some regional-scale contributions from orography. Among other areas they have found a 2006-2007 winter mean $17-23 \mathrm{~km} E_{\mathrm{p}}$ maximum above Japan and suggested that it is due to orographic waves coinciding with strong subtropical jet wind speeds in this area.

McDonald et al. (2010) studied geographic variation of the RMS (root mean square) temperature difference between pairs of FORMOSAT-3/COSMIC profiles, and the maps of RMS at 15 and $30 \mathrm{~km}$ altitude show enhancements in the northern hemispheric subtropics in the vicinity of the Gulf of Mexico and the Kuroshio stream. These regions have previously been identified as regions of strong gravity wave activity associated with convection (Preusse et al., 2001; Jiang et al., 2004; Preusse and Ern, 2005). Their results demonstrate that IGW activity dominates the variability observed in stratospheric temperature at time and spatial scales often used in validation studies, and they suggested that much of the seasonal variability observed at higher altitudes may be due to changes in the IGW propagation conditions in the lower stratosphere, while the wave field may be particularly affected by changes in the zonal wind field between 15 and $25 \mathrm{~km}$; in particular, longer horizontal wavelength waves (with smaller phase speed $c_{\mathrm{p}}$ ) may be preferentially removed by critical level filtering in this region.

Wang and Alexander (2010) presented global maps of seasonal mean IGW amplitude, vertical and horizontal wavelength, intrinsic frequency to Coriolis parameter ratio and horizontal wave propagation. Contoured maps of December 2006 to January 2007 vertical wavelengths in the altitude range of 17.5-22.5 km reveal that in our area of interest the leading mode has shorter vertical and horizontal wavelength than in other equivalent latitudes areas while having comparable amplitude. This might suggest higher buoyancy frequency (stronger stratification) values in the area of interest, or this could be an effect of different IGW sources or different background wind structure in this region.

Faber et al. (2013) calculated momentum fluxes connected with IGWs together with their vertical and horizontal wavelengths using sets of three co-located FORMOSAT3/COSMIC RO profiles. Their results show that in summer 2006 as well as in winter 2006/2007 there are regions of longer dominant vertical and horizontal wavelength and corresponding increased momentum flux above our region of interest in the altitude range of $20-30 \mathrm{~km}$.

Wright and Gille (2013) used the S-Transform method to allow for the detection of multiple overlapping waves, and they found that including these waves changes the observed distribution of IGW momentum flux. An overall $68 \%$ increase in measured momentum flux was observed for the $20-30 \mathrm{~km}$ altitude range, with significant regional variability. Among others, they found enhancement of the relative importance of the Himalayas on a global scale.

Wright et al. (2011) have compared HIRDLS, COSMIC and SABER for the detection of stratospheric gravity waves and concluded that, taking into account different vertical resolution of these instruments, all of them reproduce each other's results for magnitude and vertical scale of waves in approximately $50 \%$ of cases, although COSMIC has a positive frequency and temperature variance bias. This should be supposedly due to the higher vertical resolution.

Using data from HIRDLS, Ern and Preusse (2012) computed spectral distribution in terms of horizontal and vertical wavenumber for IGW momentum flux. They labelled the southern edge of our area of interest as a deep convection 
area, and at $25 \mathrm{~km}$ altitude they computed mean IGW momentum fluxes (from June to August) to range from -2.7 to $-3.2 \log 10 \mathrm{~Pa}$ from south to north in the area, and these values do not stand out in comparison to values in other regions. For November, Ern et al. (2011) found one of the largest IGW momentum flux values north of Japan at the altitude of $30 \mathrm{~km}$. Their analysis of SABER/TIMED gravity wave momentum flux reveals increasingly interesting patterns with altitude up to $70 \mathrm{~km}$ above the region of interest.

Zhang et al. (2012) studied the activity of IGWs from SABER/TIMED temperature profiles between January 2002 and December 2009. For vertical wavelengths between 2 and $10 \mathrm{~km}$ integrated over a layer between 21 and $45 \mathrm{~km}$ they found in all seasons only small values of $E_{\mathrm{p}}$, not exceeding $1.5 \mathrm{~J} \mathrm{~kg}^{-1}$ above the area of interest. Further south they identified the region of Southeast Asia as a region with large $E_{\mathrm{p}}$ values corresponding to the tropical deep convection.

Ern et al. (2013) introduced projects having addressed IGWs in the priority program Climate and Weather of the Sun-Earth System (CAWSES). They showed global distributions of IGW (vertical wavelength range 4-10 km) momentum flux derived from SABER temperature data at $25 \mathrm{~km}$ altitude, averaged over the years 2002-2006 for the months of January, April, July and October. They did not find exceptionally large fluxes above the northwestern Pacific region in any season. Again, south of the area, in April, July and October there is a clearly visible local maximum region likely due to IGWs generated by deep convection.

John and Kumar (2012) studied IGW activity from the stratosphere to the lower mesosphere in terms of their potential energy. Averaging SABER data from 2003 to 2006 and in the region $20-60 \mathrm{~km}$ they presented monthly mean global maps of IGW potential energies. Maximal values are ranging up to $120 \mathrm{~J} \mathrm{~kg}^{-1}$ (above the Andes and above Scandinavia in winter) but in the area of interest the IGW potential energy does not exceed $20 \mathrm{~J} \mathrm{~kg}^{-1}$ in any month and interestingly there are not expected areas of higher $E_{\mathrm{p}}$ connected with deep convection. Potential energy averaged in the $60-80 \mathrm{~km}$ height range exhibits almost the same distribution across the globe.

Baumgaertner and McDonald (2007) highlighted the role of background winds in the gravity wave distributions and there are some papers where information about wind patterns above the area of interest can be found. Oberheide (2002) computed zonal and meridional geostrophic wind fields in the altitude range of $20-90 \mathrm{~km}$ from the Cryogenic Infrared Spectrometers and Telescopes for the Atmosphere (CRISTA) and we can see on the 9 November 1994 by zonal winds at $1 \mathrm{hPa}$ (above the upper boundary of RO analysis) that the jet avoids the region of interest. Verkhoglyadova et al. (2014) computed geostrophic wind maps from a simulated data set based on COSMIC RO for the upper troposphere-lower stratosphere region and for example in January 2007 one can see at the $200 \mathrm{hPa}$ constant dry pressure surface the highest zonal wind speeds starting above Japan and continuing fur- ther eastward above the Pacific. This feature also emerges in January 2009 as shown by Scherllin-Pirscher et al. (2014) (their Fig. 2). The $200 \mathrm{hPa}$ level is below the usually defined lower boundary of GPS RO IGW analyses, but conditions of the upper troposphere influence the upward propagation of IGWs into the stratosphere.

\section{Data and methodology}

To describe the background climatology over our region of interest, we have analysed the MERRA (Modern Era Reanalysis for Research and Applications; Rienecker et al., 2011) and JRA-55 (Japanese 55-year Reanalysis; Ebita et al., 2011) series for the 1979-2013 time interval. The data were analysed on a monthly basis in the horizontal resolution of $1.25^{\circ} \times 1.25^{\circ}$. We have studied temperature, geopotential height, ozone mixing ratio and zonal wind. To examine the annual cycle amplitudes, we used a continuous wavelet transform (CWT; e.g. Torrence and Compo, 1998; Percival and Walden, 2006) that delivers the amplitude of a detected oscillation as a function of both frequency and time. To study spatial variation of the annual cycle amplitude, we applied an extension of the CWT - the pseudo-2-D wavelet transform (Pišoft et al., 2009; Pisoft et al., 2011). The analysis was computed using the Morlet mother wavelet, with the wavenumber $\Omega_{0}$ equal to 6 . To construct the $95 \%$ confidence intervals, we have employed a significance test by Torrence and Compo (1998). For the interpretation only statistically significant results outside the cone of influence were selected.

To investigate the IGW activity in the area of interest compared to the other regions, we have analysed L2 level FORMOSAT-3/COSMIC RO data (Anthes et al., 2008)) on a $3^{\circ} \times 3^{\circ}$ grid from 2007 to 2010 . GPS RO data proved to be a very useful tool for atmospheric monitoring and studies. They are frequently used for analyses of the IGWs in the upper troposphere-lower stratosphere region. GPS data are characterised by a good vertical resolution providing atmospheric profiles with global coverage under all weather and geographical conditions (Foelsche et al., 2008). Atmospheric density is the first quantity of state gained in the GPS RO retrieval process and is not burdened by any additional assumptions, as it is the case, e.g., with temperature. According to the linear theory of the IGWs, a separation between a small wave-induced fluctuation and background field has to be performed. As shown by Marquardt and Healy (2005), smallscale fluctuations of dry temperature RO profiles can be interpreted with certainty as IGWs, when the vertical wavelength is equal or greater than $2 \mathrm{~km}$. To separate the perturbations, we applied a method described in Šácha et al. (2014) for the density background separation. The method is based on fitting the buoyancy frequency height profile and on the consequent analytical derivation of the background density functional dependence on altitude. After the background sep- 
aration and normalisation of the disturbances, we obtain one normalised density perturbation height profile for each occultation.

Šácha et al. (2014) argues that the usage of density profiles bears many advantages, for example the inclusion of non-hydrostatic waves. Those are the waves with frequencies close to the buoyancy frequency and with phase line slopes significantly different from zero (Sutherland, 2010). These waves are often too small to be resolved by circulation models and according to CCMVal (2010) such unresolved $(10-1000 \mathrm{~km})$ IGWs play a significant role in stratospheric circulation, driving nearly a quarter of the stratospheric circulation in comprehensive models.

The lower boundary of analysed IGW vertical wavelengths should be normally determined by the Nyquist frequency arising from the vertical resolution of the occultation technique, but since we are more interested in the relative distribution of IGW activity than the absolute values we are not making any vertical wavelength cut-off at the lower boundary. We assume the noise to be almost independent of the geographical location, which is, however, generally not true (Marquardt and Healy, 2005) and so our calculated distributions of IGW activity can be partly affected by the spatio-temporal distribution of noise. The discussion on adequate choice of the wavelength cut-off for studying gravity waves through RO measurements is still open (Luna et al., 2013); thus, we decided not to make any cut-off even at the upper boundary of vertical wavelengths. Considering the geographically variable vertical extent of our analysis (from the tropopause up to $35 \mathrm{~km}$ ), we must note that the IGW modes with vertical wavelengths comparable or greater than the vertical range $(\approx 15 \mathrm{~km}$ and more) will be increasingly underestimated with increasing tropopause altitude. But because these modes have vertical wavelengths many times longer than the most energetic modes $(2-5 \mathrm{~km}$ in the lower stratosphere; Fritts and Alexander, 2003), we do not expect this underestimation to significantly affect our results.

Because single GPS measurement provides just a snapshot of an actual atmospheric state without any direct information from the cotangent-phase space (e.g. velocity), the choice of derivable diagnostic quantities is quite restricted. Many authors used the energy density as a measure for wave activity (e.g. Tsuda et al., 2000; Ratnam et al., 2004; De la Torre et al., 2006; Hei et al., 2008). We have computed the potential energy density of disturbances per unit mass $\bar{E}_{\mathrm{p}}$ using the formula provided by Wilson et al. (1991):

$\bar{E}_{\mathrm{p}}=\frac{1}{2} N^{2}\left\langle\xi^{2}\right\rangle=\frac{1}{2}\left(\frac{g}{N}\right)^{2}\left\langle\frac{\rho^{\prime}}{\bar{\rho}}\right\rangle^{2}$,

where $\xi$ is a wave-induced Lagrangian displacement, $N$ the buoyancy frequency, $\rho^{\prime}$ the density perturbation and $\bar{\rho}$ the background density; $\left\langle()^{2}\right\rangle$ denotes a variance. For a single profile, the variance is computed in altitude and the symbol \langle\rangle means averaging across the whole altitude range of the analysis (from tropopause up to $35 \mathrm{~km}$ ). To obtain the results also at particular height levels, the variance is then computed across the ensemble of occultations belonging to the grid at those levels.

Tsuda et al. (2000) referred to VanZandt (1985) for a theoretical evidence that the ratio between kinetic (mostly horizontal) and potential energy is approximately constant and equal to the spectral index $p$ (roughly $5 / 3$ to 2 ) and then concludes that under the linear theory it is possible to estimate total energy from temperature observations only. If this is true for temperature perturbations it should then naturally stand for density as well. Tsuda et al. (2000) further compared the climatological behaviour of potential (from GPS Meteorology experiment) and kinetic energy of disturbances (from middle and upper atmosphere, MU, radar) around Japan and found reasonable agreement.

Ratnam et al. (2004) validated potential energy of disturbances computed from the GPS RO dry temperature profiles versus radiosondes data. They found that at most of the heights, values estimated from ground-based instruments are showing higher values. One of the reasons for this is the lower vertical resolution of GPS RO compared with radiosondes or lidar. This situation should slightly improve when using the density profiles, mainly due to the higher spectral power at lower vertical wavelengths (Šácha et al., 2014). Another source of reduction is the viewing geometry with respect to the wave fronts (e.g. Lange and Jacobi, 2003).

Nevertheless, Tsuda et al. (2000), among other approximations made by VanZandt (1985), whose discussion is beyond the scope of this manuscript, did not explicitly mention a crucial assumption of theoretical saturated spectra in the interval used for the derivation of the constancy of wave kinetic to potential energy ratio. For a single IGW in the rotating frame of reference, however, the equipartitioning holds between the kinetic energy in the $x-z$ plane and the sum of kinetic energy in the $y$ direction and potential energy (consequence of the out of phase motion in $y$ direction vs. in the $x-z$ plane). So, for a single IGW, the partitioning ratio between wave kinetic and potential energy is dependent on its intrinsic frequency (Bühler, 2014). Approximately, we can write

$\bar{E}_{\mathrm{p}}=\left(1-\frac{f^{2}}{\hat{\omega}^{2}}\right) \bar{E}$,

where $\bar{E}$ is the mean wave energy, $f$ the Coriolis parameter and $\hat{\omega}$ the intrinsic frequency. We will come back to the question of how good a proxy for wave activity potential energy is in the discussion, after which we will see in our results an indication of possible masking of regions with important IGW activity.

For this purpose we have employed two characteristics (novel in GPS RO studies) to access the stability of the wave field. A stratified fluid may become unstable if disturbances can overcome the stabilising effect of buoyancy by drawing kinetic energy from the mean flow. The necessary condition 
for such a dynamical instability is (Sutherland, 2010)

$R i_{g}=\frac{N_{0}^{2}}{s_{0}^{2}}<1 / 4$.

Here $R i_{g}$ is the gradient Richardson number, $N_{0}$ the background stratification frequency and $s_{0}$ the background wind shear. Senft and Gardner (1991) have estimated the gradient Richardson number by appropriately scaling the variance of the vertical gradient of relative density perturbations, assuming that the background wind shear is negligible, and using the polarisation relations for IGWs they had

$R i_{g}=\frac{g^{2}}{N^{4}}\left\langle\left[\frac{\partial}{\partial z}\left(\frac{\rho^{\prime}}{\bar{\rho}}\right)\right]^{2}\right\rangle$.

In our analysis we search for local values instead of computing the vertical variance.

Another characteristic is used to access the overturning instabilities. According to Sutherland (2010) we define $\sigma$, the maximum growth rate of disturbances arising from Rayleigh-Taylor convective instability, as

$\sigma^{2}=\frac{g}{\rho_{0}}\left(\frac{\mathrm{d} \bar{\rho}}{\mathrm{d} z}+\frac{\partial \rho^{\prime}}{\partial z}\right)$.

The value of $\sigma$ is real when waves drive the fluid to be overturning. Nevertheless, for convective instability to occur (for the waves to overturn and break), the convection growth should be faster than the wave frequency (Sutherland, 2010). For hydrostatic waves, only the overturning condition suffices to access the stability.

In reality there is an interplay between different types of instabilities and interactions and therefore we do not use these characteristics to find areas or seasons where values exceed the exact threshold and turbulence and mixing occurs. In fact, it is natural to expect the values of those characteristics to be below their threshold because of the effect of the observational filter (Lange and Jacobi, 2003; Trinh et al., 2015), and also the probability that the occultation takes place at the exact time IGW breaking is low. Instead, we use these characteristics as a comparative hint to study the geographical distribution of possible IGW effects on the stratosphere, mainly comparing values in the region of interest with other areas. The lower the $R i_{g}$ value and the higher the value of $\sigma^{2}$, the higher the probability that breaking of IGWs is underway and that waves are interacting with the mean state in a region.

For all results, to illustrate large intervals of irregularly distributed values, we have followed the approach applied by Pišoft et al. (2013). For the frequency and IGW characteristics, we use a colour scale derived from the relative frequency of the detected values. The results were sorted according to their values and subsequently split into 100 equally large groups. The groups define intervals for particular colours and every colour then represents the same number of identified values. Using this approach, even subtle features of the illustrated fields can be displayed. On the other hand, this technique leads to a highly non-uniform scaling that has to be reflected in the subsequent interpretation of the results.

\section{Results}

Here, we present selected results consisting of (a) presentation of the anomaly over the region of interest using the wavelet analysis and climatology of the annual cycle, (b) IGW analysis describing the spatial distribution of potential energy of the disturbances, (c) analysis of the Richardson number and sigma indicating wave breaking and (d) study of possible wave sources with the use of cumulative wind rotation analysis. Supplement and more detailed results of analyses (a)-(d) are presented in the Supplement.

\subsection{Anomaly over the northern Pacific-eastern Asia region}

Figure 1 illustrates the distribution of the wavelet power linked to the annual cycle amplitude in the temperature and the zonal wind field at $30 \mathrm{hPa}$ using the MERRA reanalysis. A region of anomalous small amplitudes is seen across the northern Pacific and eastern Asia. This anomaly is found for levels from about 50 up to $10 \mathrm{hPa}$ for temperature and up to $1 \mathrm{hPa}$ for zonal wind (for details see Figs. S1-S3 in the Supplement).

The region where the anomaly is detected can also be linked to other distinct characteristics found in climatological fields. Considering the mean annual cycle of the temperature, zonal wind and ozone, we see very specific patterns in the stratosphere over the northern Pacific and East Asia region coinciding with the area of interest in this study.

Figure 2 presents the 1979-2013 mean seasonal averages at $30 \mathrm{hPa}$ from MERRA (for other levels see Figs. S4S6 in the Supplement). In northern hemispheric winter and (weaker expressed) in spring and autumn, there is an eastward wind minimum over the northern Pacific. The westerly jet is shifted northward, which results in a wave-1 pattern. A similar pattern can be found in the southern hemispheric midlatitudes where the jet stream is shifted slightly poleward at similar longitudes.

Seasonal averages of the temperature series at the $30 \mathrm{hPa}$ (Fig. 2) reveal a region of the high autumn and winter temperatures over the area of interest. A similar structure is found from about $100 \mathrm{hPa}$ up to $10 \mathrm{hPa}$ (for details see Fig. S5 in the Supplement). A similar anomaly is found also in the Southern Hemisphere south of Australia, but most strongly in southern hemispheric spring. For levels above about the $10 \mathrm{hPa}$ there is no longer such a well-marked pattern in the temperature field as in the lower levels. This can be connected to the higher temperatures in lower levels, which lift the $10 \mathrm{hPa}$ level with respect to other locations. In the zonal 

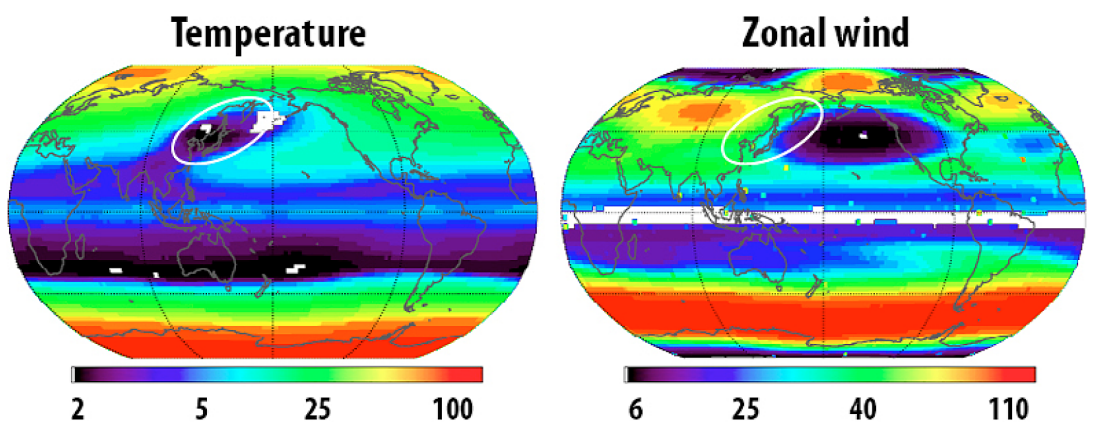

Figure 1. Annual cycle amplitudes of temperature (left) and zonal wind (right) at $30 \mathrm{hPa}$. The non-linear colour scale used represents the square root of the wavelet power in $\mathrm{K}$ for temperature and in $\mathrm{ms}^{-1}$ for zonal wind.

wind field, the jet stream northward shift is still clearly visible even at the $10 \mathrm{hPa}$.

Figure 2 also illustrates the mean annual cycle in the ozone series at $30 \mathrm{hPa}$. There is a region of enhanced ozone concentrations above the area of interest during the whole year except for northern hemispheric summer. Maxima in the ozone concentration fields are shifted northward above the area of interest in northern hemispheric winter, again producing the wave-1 pattern. During autumn and spring, the maxima of concentration are found over the area of interest. In general the ozone concentrations above the area of interest are among the highest in northern hemispheric mid- to polar latitudes.

Specific patterns found in the mean climatology in Fig. 2 can be considered as the signature of an enhanced downwelling of the equatorial air reaching more northward over the northern hemispheric Pacific. In the next section we are looking for a stronger IGW activity above the analysed region, because such localised stronger wave activity region could hypothetically lead to a longitudinally distinct intensified branch of the Brewer-Dobson circulation. Also, the wave-1 pattern in the ozone, temperature and zonal wind fields at $10-30 \mathrm{hPa}$ suggests that the area of interest could play an important role in the dynamics of the polar vortex making it zonally asymmetric and forcing the wave-1 structure.

\subsection{IGW Analysis}

It should be noted that the time interval of the analysis of the MERRA data set is much longer than the interval of the following IGW analysis. For consistency, we computed annual cycle amplitudes and mean seasonal averages also for the period 2007-2010 (not shown here). The results show that the above-described features are similar for this short period comparing to the original one. Kozubek et al. (2015) studied the longitudinal distribution and long-term trend of northern hemispheric stratospheric winds and identified a dominant effect of the Aleutian high (our region of interest is located at its western border in the stratosphere). They found that the trends of meridional winds connected with the Aleutian high are independent of sudden stratospheric warmings (SSW) or QBO. They observed intensification of the winds in the period of ozone depletion deepening (1970-1995) and weakening of the winds in the period of ozone recovery (19962012). However, there is an indirect dependence of the winds on QBO, as the solar cycle influence is pronounced mainly for the west phase of QBO.

Figure 3 shows the mean potential energy averaged across the whole vertical profile and averaged over 4 years (20072010). The $\bar{E}_{\mathrm{p}}$ values over eastern Asia are as large as in the equatorial area (including a possible Kelvin wave contribution there) or in regions with significant topography (e.g. the Andes). The area of enhanced $\bar{E}_{\mathrm{p}}$ spreads out from the Himalayas to the east and above the region of interest.

Other important features are visible in the seasonal means of the $\bar{E}_{\mathrm{p}}$ averaged across the whole vertical extent (Fig. 4). While in winter and spring the area of interest lies in the region of high $\bar{E}_{\mathrm{p}}$ values extending over the whole latitude circle (except for the northern Pacific) and strengthening eastward of the Himalayas, in summer there is a region of low values over the broad region of the Pacific Ocean. Finally, in autumn, there is a unique and localised area of the highest $\bar{E}_{\mathrm{p}}$ values (ranging up to $6 \mathrm{~J} \mathrm{~kg}^{-1}$ ) in the Northern Hemisphere.

Analysing this pattern on a monthly basis (Fig. 5), we may see that in September there is an area of low $\bar{E}_{\mathrm{p}}$ above the northern Pacific while over north-eastern Asia there is a weakly defined area of higher $\bar{E}_{\mathrm{p}}$ values around $2.5 \mathrm{~J} \mathrm{~kg}^{-1}$. This region expands eastward above Japan in October and the wave activity strengthens. In November, there is a welldefined area of northern hemispheric maximal $\bar{E}_{\mathrm{p}}$ above the region of interest. In December, we can see a typical winter pattern of high $\bar{E}_{\mathrm{p}}$ values ranging approximately from $\mathrm{Hi}-$ malayas while strengthening towards the analysed region.

In fields for individual pressure levels (Fig. S7 in supplement), the described patterns over the area of interest are detected from $70 \mathrm{hPa}$ up to the $6 \mathrm{hPa}$ level. All these results support the hypothesis of special IGW activity in the analysed area.

The specific annual cycle of the stratospheric conditions over the area of interest described in the previous chapter is in 

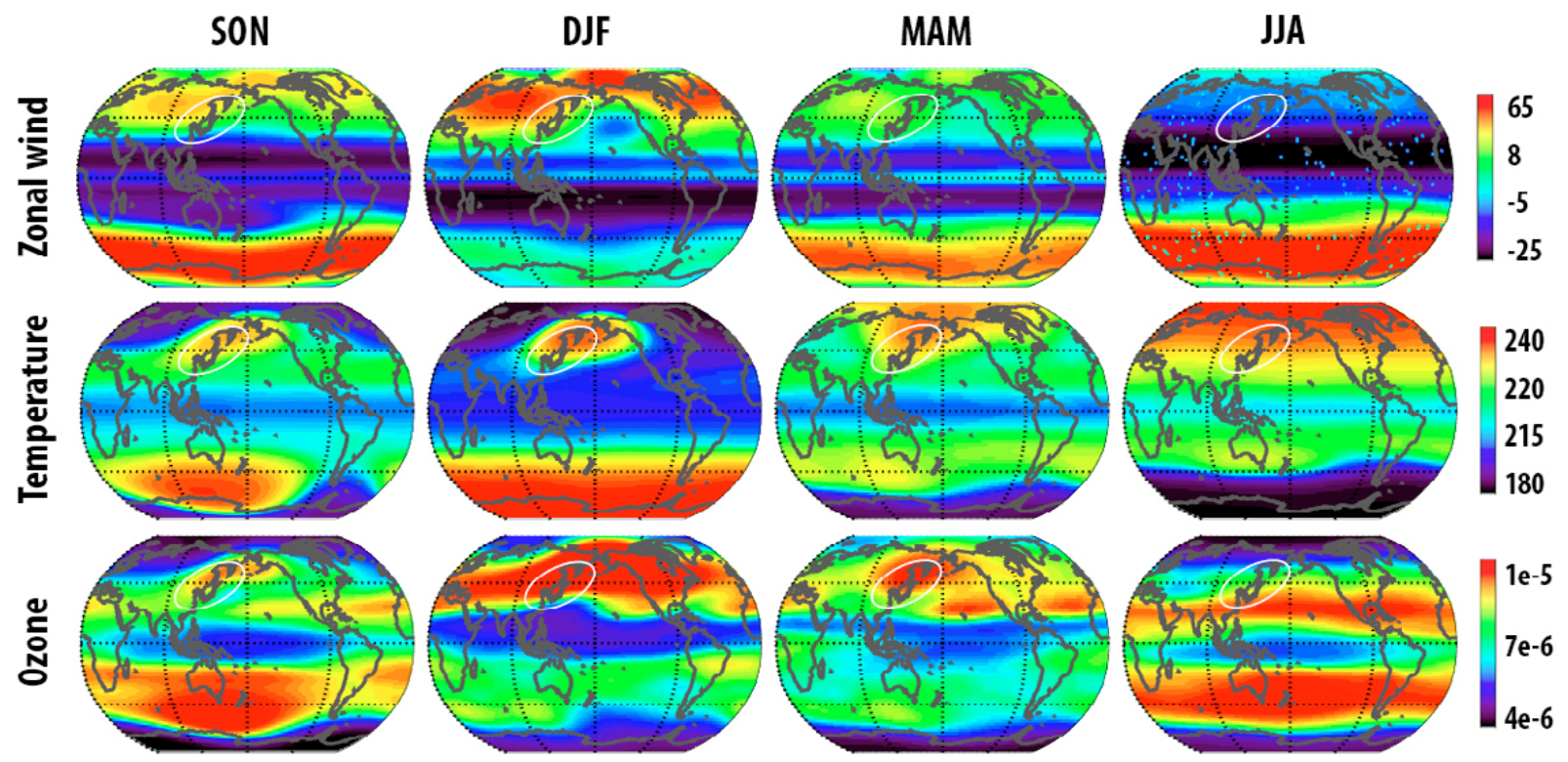

Figure 2. Seasonal averages of zonal wind in $\mathrm{ms}^{-1}$, temperature in $\mathrm{K}$ and ozone mass mixing ratio in $\mathrm{mg} \mathrm{kg}^{-1}$ for $1979-2013$ using MERRA reanalysis (non-linear colour scale used).

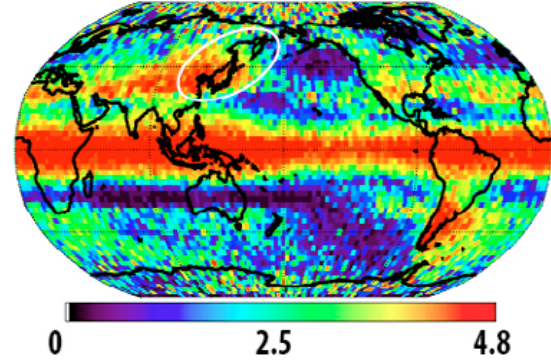

Figure 3. Annual mean of the potential energy in $\mathrm{J} \mathrm{kg}^{-1}$ averaged across the whole vertical profile for 2007-2010 (non-linear colour scale used).

accordance with this wave activity cycle. Wave activity generally precedes changes of the residual circulation and its dynamical effects (e.g. Kuchař et al., 2015) and in the distribution of temperature and zonal wind the region is pronounced most significantly in winter. However, to quantify the role of such localised wave activity maxima for the specific dynamics leading to the anomalous annual cycle amplitudes in this region, it would be necessary to have information on time evolution of the wave activity and distribution of dissipative processes in the region to quantify a wave-mean flow interaction in the sense of generalised Eliassen-Palm theorem (for zonal averages, see e.g. Andrews et al., 1987, Eq. 3.6.2). But this approach cannot be applied having the information from observations only.
Therefore, further analysis is focussed on the stability of the wave fields in order to find regions of possible wave breaking and interaction with the mean state of the atmosphere. This can help to quantify the relative importance of this region and may give a better view on its dynamical effects on the stratospheric circulation. The analysis is followed by a discussion of the types and sources of IGWs in this region especially in October and November, based on study of prevailing surface wind directions and the rotation of the wind (change of wind direction) with height.

\subsection{Wave breaking indication}

Figure 6 presents the distribution of the gradient Richardson number at three levels between 30 and $10 \mathrm{hPa}$ in April and May. The fields are shown for those months when the $\bar{E}_{\mathrm{p}}$ values in the area of interest do not stand out against other regions. One can see from Fig. 6 that at each altitude considered the gradient Richardson number $\left(R i_{g}\right)$ is small over the area of interest. Further analysis showed that, except for March, June, July, August, and September, the lowest $R i_{g}$ values are over the area of interest at all levels from 70 up to $6 \mathrm{hPa}$ (for details see Figs. S8-S11 in the Supplement). This suggests that the wave/wind fields in this region are closer to dynamical instability than in other regions. An interesting pattern emerges in October and November (Fig. S8 in Supplement) and at some pressure levels also in the winter season (Fig. S11 in the Supplement). Furthermore, low $R i_{g}$ values are located not only above the analysed region but also extending along the western Pacific coast and then southward along the eastern Pacific coast to Northern America. This is in agreement with the wave-1 pattern of the jet stream and the 

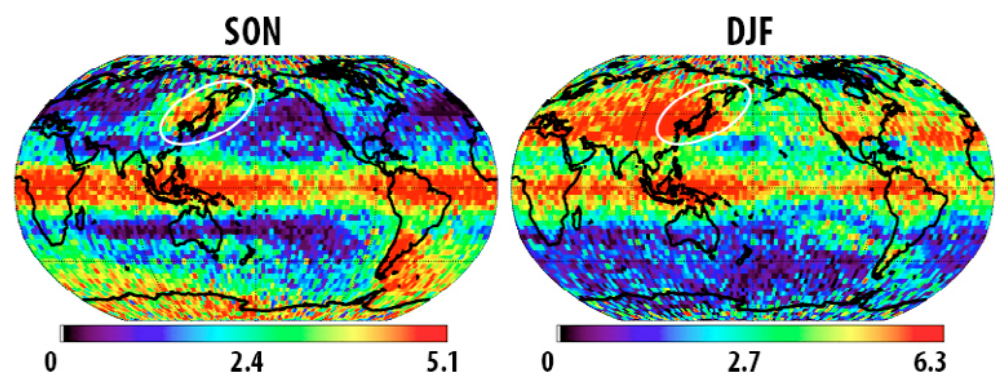

MAM
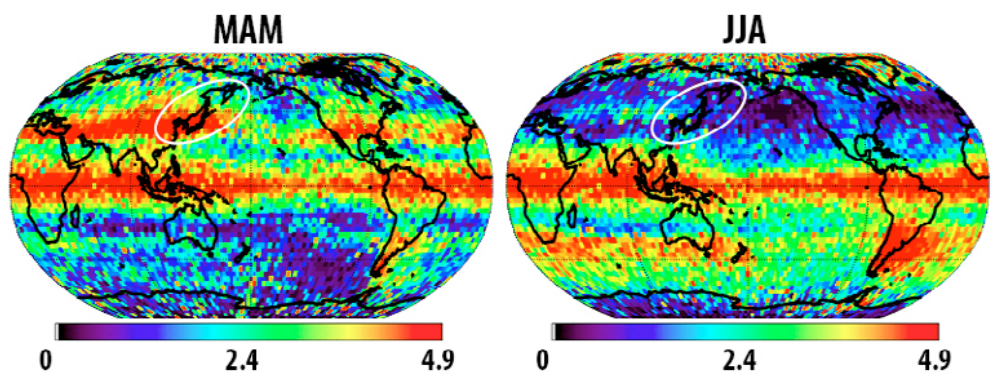

Figure 4. Seasonal means of the potential energy in $\mathrm{J} \mathrm{kg}^{-1}$ averaged across the whole vertical profile for 2007-2010 (non-linear colour scale used).
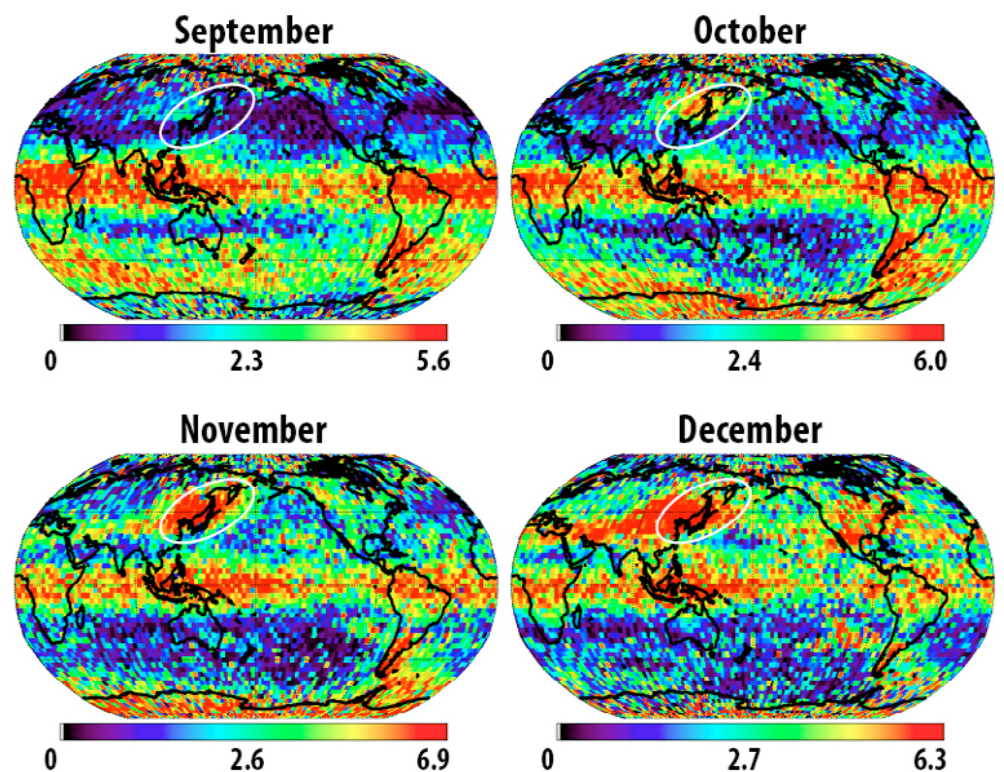

Figure 5. Selected monthly means of the potential energy in $\mathrm{J} \mathrm{kg}^{-1}$ averaged across the whole vertical profile for 2007-2010 (non-linear colour scale used).

jet location shown in Fig. 2: low $R i_{g}$ values are detected even in the areas where the wave activity is not especially strong. Suitable background conditions, i.e. strong wind shear, can bring the waves close to instability and allow them to affect the mean flow.

Results of the analysis of the sigma, i.e. the RayleighTaylor convective instability disturbances growth rate are illustrated in Fig. 7. The distribution of the maximum detected in the sigma squared profiles (uppermost row) is presented together with the distribution of selected secondary maxima in each grid box. The results are calculated in such a way that within all of the occultation profiles in a selected grid box and time interval we look for the highest sigma squared value, consider it (noting its altitude as well) as the first maximum and then we look for the second highest value, etc. The secondary values are often found in different profiles or are from the same profile but located at lower altitudes. Positive values of sigma squared indicate convective instability, so that we observe negative values only; however, small magnitudes of $\sigma$ indicate regions of weak stability. Figure 7 fur- 

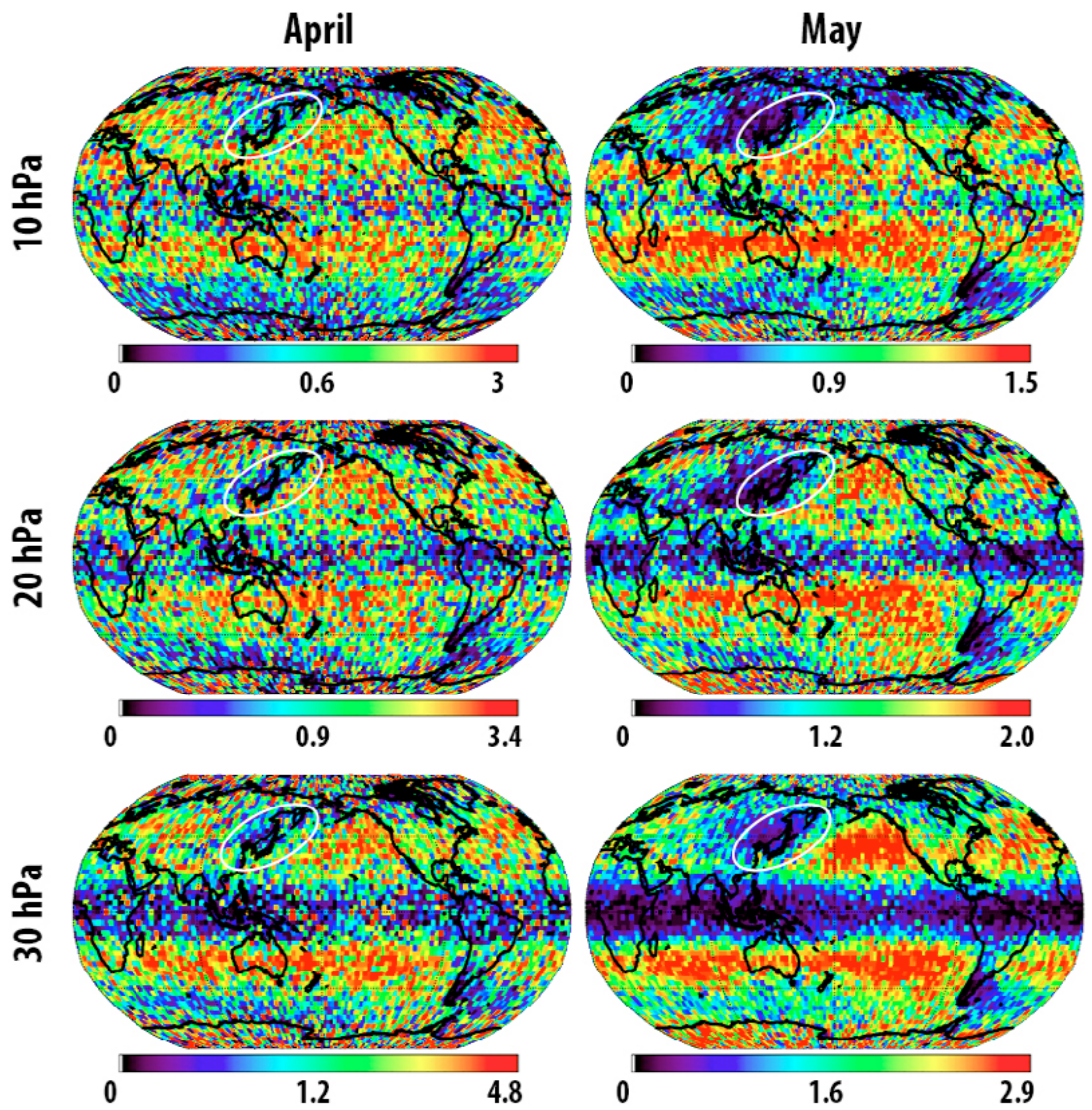

Figure 6. Selected monthly means of the gradient Richardson number at 10, 20 and $30 \mathrm{hPa}$ for 2007-2010 (non-linear colour scale used).

ther accentuates the importance of the area of interest. The maximum $\sigma$ values detected over the region of interest (often together with its coastline extension) are a dominant feature of the maps. These findings indicate a vertically robust and persistent breaking of IGWs. Also the altitudes of the sigma squared maxima over the region of interest are among the lowest detected ones (around $25 \mathrm{~km}$ altitude, for details see Figs. S12 and S13 in the Supplement), suggesting that breaking begins at lower levels in this region. Another interesting result is the detection of high sigma squared maximum values in the stratosphere over the summer polar latitudes. These are found for the first maximum but are better visible for secondary maxima at lower altitudes. This finding is in line with Baumgaertner and McDonald (2007), who attributed the small amount of summertime potential energy to lower level critical filtering.

\subsection{Possible wave sources}

The IGW spectrum is shaped not only by different sources but also reflects tropospheric background conditions contributing to filtering of various gravity waves (Fritts and Alexander, 2003). This can be easily applicable to the orographic gravity waves that are critically filtered when the wind speed is zero. This condition is fulfilled in the case of directional shear exceeding $180^{\circ}$. Above regions where this is fulfilled, one can rule out the possibility of orographic gravity wave modes contributing to the observed IGW activity. Vice versa, regions of small wind rotation (change of wind directions between levels) from the lower levels are favourable for vertical propagation of orographic waves. Alexander et al. (2009) argued that higher stratospheric orographic wave activity is expected to be observed when there is relatively little rotation between the surface and $400 \mathrm{~K}$ isentropic surface.

We studied the wind direction and its change between $975 \mathrm{hPa}$ and higher levels. The results are shown in Fig. 8 for November 2008. All results are presented in Figs. S14-S15 in the Supplement. The analysis shows that in the region of interest the wind direction changes only little. Only in June, July and August are the orographic gravity waves likely to be completely filtered out of the spectra before reaching the lower stratosphere $100 \mathrm{hPa}$ level above the analysed region.

The direction of the surface winds suggests orographic formation of the IGWs due to the topography of Japan, Sachalin, Korean Peninsula or eastern Asia coastline. The significance of this topography is enhanced by the contrast with the ocean surface. Considering the optimal conditions for propagation into the stratosphere and the topography suitable for emitting 

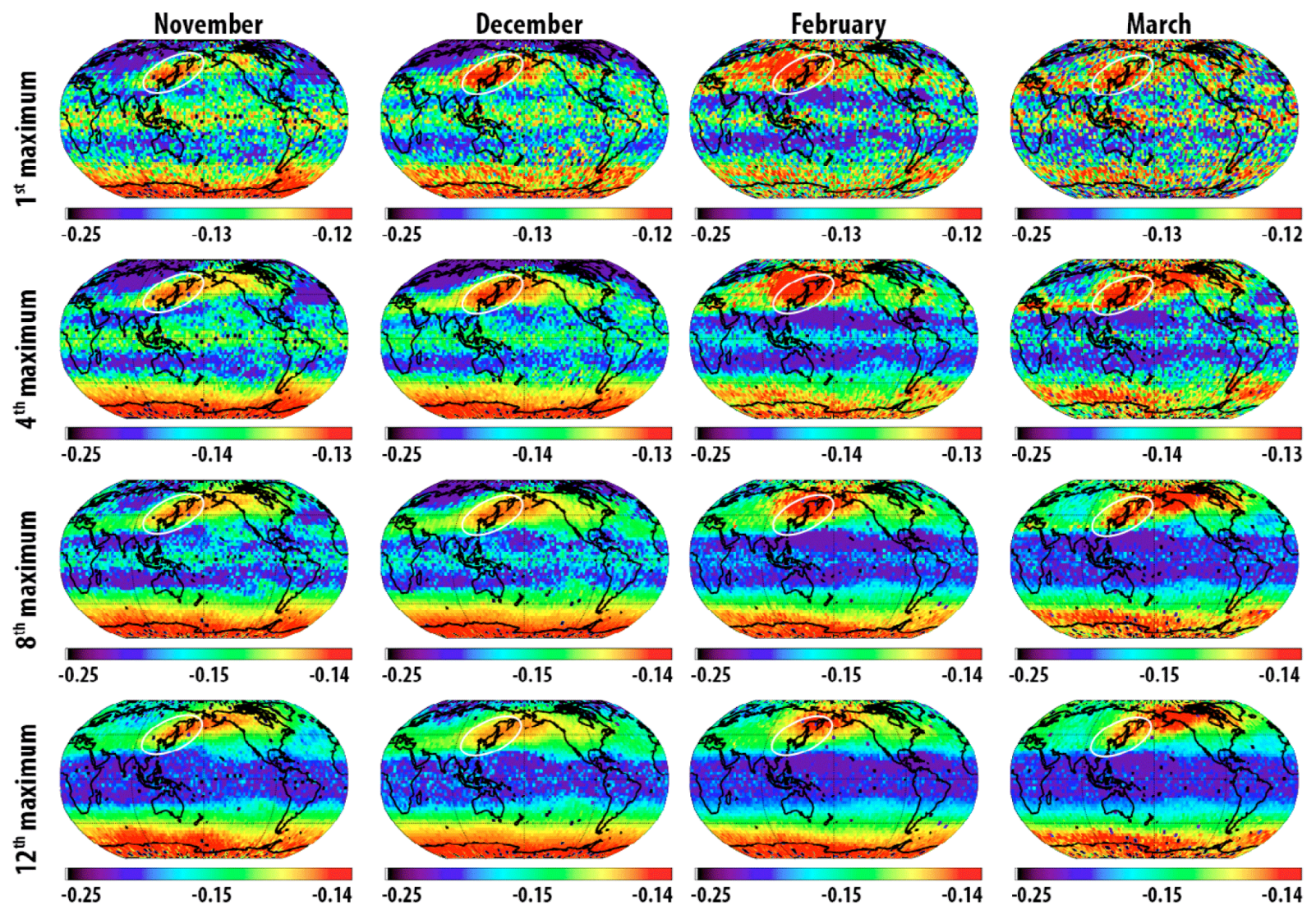

Figure 7. Selected monthly means of primary and selected secondary (i.e. higher order) sigma squared maxima in $s^{-2}$ for $2007-2010$ (non-linear colour scale used).
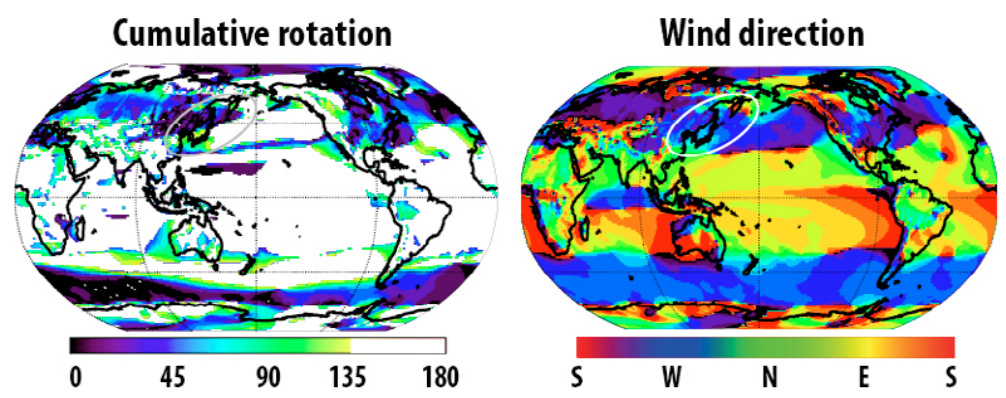

Figure 8. Cumulative rotation of wind from 975 to $30 \mathrm{hPa}$ (left) and prevailing wind direction st $975 \mathrm{hPa}$ (right). Computed from JRA-55 for November 2008.

large amplitude orographic waves, we conclude that a significant part of the measured IGW spectra in the area of interest may consist of orographic IGWs. This is in line with findings of Alexander et al. (2008) regarding this region.

Another source of IGWs in this region, which is of special interest because of their autumn appearance, is convective activity connected with the Kuroshio current. Its role in forcing IGWs has been pointed out, e.g., by McDonald et al. (2010) and Jia et al. (2014). Ern and Preusse (2012), Zhang et al. (2012) and Ern et al. (2013) labelled an area to the south of the region of interest as a deep convective region with large gravity wave activity. Taking into account that the meridional propagation is predominantly northward (Horinouchi and Tsuda, 2009), we may conclude that these waves could play a role in the region of interest mainly in spring and summer.

Alexander et al. (2009) argued that the FORMOSAT3/COSMIC observed IGW variance in the stratosphere likely depends upon a combination of orographic waves, Doppler shifting of tropospheric source waves and possibly some in situ stratospheric wave generation. 
Considering the wind field in the region of interest (seasonally dependent location of the subtropical westerly jet and the polar front jet in the upper troposphere-lower stratosphere), the Doppler shifting must play a role in amplifying wave amplitudes while propagating upwards, and it may also be responsible for one of the possible reasons for the enhanced wave activity in this region.

Finally, in connection with the jet location above the region of interest, we can expect a strong contribution to the IGW spectrum from spontaneous emission processes (Plougonven and Zhang, 2014). Evidence for this claim can be found, e.g., in Hirota and Niki (1985) and Sato (1994), who analysed middle and upper atmospheric radar data (located at Shigaraki, Japan, falling into our region of interest) and who found inertia IGWs propagating upward and downward from the jet stream. Orographic waves were also identified.

As a curiosity, according to Mohri (1953), during the colder season the subtropical jet stream reaches its maximum intensity south of Japan, while the polar front jet is located north of the Tibetan Plateau. Moreover, these jets sometimes merge (mainly in winter) and create extremely thick frontal layers. Such episodes can become a very interesting and unique source of IGWs in this area.

\section{Discussion}

The specific dynamics, as well as the IGW hotspot area, has, to our knowledge, not been identified in previous observational or theoretical studies. In the following, we shall discuss possible reasons for this, together with a discussion of the usage of $E_{\mathrm{p}}$ as a wave activity proxy, and possible implications of such a unique wave activity region for the large-scale dynamics and transport in the middle stratosphere.

\section{1 (Un)masking the IGW hotspot area}

There are a lot of satellite studies of the global distribution of IGW activity. But autumn, the season of most unique wave activity in the region of interest, is often left out because the main focus is usually laid on the winter season. Generally, to our knowledge, there are only a few monthly analyses of the mean annual cycle of gravity wave activity. This can account for masking the significance of the region of interest.

One of the unique aspects of our analysis is also that we were purposefully looking for anomalous wave activity in the region of interest, which was hypothesised due to anomalies found in the zonal wind, temperature and ozone fields.

The methodology of our analysis is novel through the use of GPS RO density instead of temperature profiles. Although the differences between IGW characteristics derived from the dry temperature and density profiles have not been studied in details yet, Šácha et al. (2014) demonstrated that in comparison with temperature the density perturbation spec- tra have higher power spectral density in the shorter vertical wavelength range below roughly $2.5 \mathrm{~km}$. Comparison in the larger wavelength region is generally inconclusive because the power spectral density there is dominated by the background separation method. How this could influence the results of our analysis will partly be discussed in the next paragraphs.

\subsection{Wave activity proxy}

Šácha et al. (2014) summarised that, unlike using GPS RO dry temperature profiles, density perturbations include contributions from non-hydrostatic waves and the obtained wave amplitudes are not additionally suppressed by the hydrostatic assumption in the retrieval. Nevertheless, the spatial distribution of non-hydrostatic waves, to our knowledge, has not been fully quantified yet. Thus, it is possible that the magnitude of the difference between temperature and density spectra can change with location. Šácha et al. (2014) found differences between temperature and density PSD (power spectral density) in the same region as we have analysed. However, in other locations and basically in all vertical wavenumber regions where the PSD slope of perturbations disagree with the slope of theoretical saturated spectra, the magnitude of differences between power spectral densities of temperature and density perturbations may vary; moreover, the validity of $\bar{E}_{\mathrm{p}}$ as a wave activity proxy is crucially connected with the agreement or disagreement of vertical wavenumber spectra and theoretical saturated spectra.

There is a long tradition of using mean wave energy as a measure for wave activity in the IGW studies using GPS RO data. However, strictly speaking, the wave energy is not a conserved quantity during the wave propagation (Bühler, 2014). To estimate it using only instantaneous temperature or density measurements, a constant ratio between mean wave kinetic and potential energy has to be assumed (VanZandt, 1985). Then the key question is whether the vertical wavenumber spectrum obtained from the GPS RO occultation can be considered as saturated to fulfil the underlying essential assumption of universal saturated spectra of IGWs.

Theory of IGW spectra generally assumes saturation at each wavenumber (Smith et al., 1987), and although the observed spectra in the middle atmosphere are influenced by the distribution of tropospheric sources and filtering due to propagation in different conditions, they appear to be close to theoretical ones when observed over long times (Fritts, 1984).

Smith et al. (1987), Allen and Vincent (1995) and Fritts and Alexander (2003) noted that mean energy and characteristic vertical wavenumber of gravity waves may experience significant variations with time and geographical location. This is due to the variations in the energy of motions at vertical wavenumbers lower than the characteristic wavenumber (around $3 \mathrm{rad} \mathrm{km}^{-1}$ in the lower stratosphere Fritts and Alexander, 2003; Tsuda et al., 1994) caused by variable 
IGW sources, mean wind, and static stability. Even VanZandt (1985) noted that lee waves are likely to be important for small values of the characteristic vertical wavenumber.

For temperature profiles in the lower stratosphere, Steiner and Kirchengast (2000) documented that the average GPS/MET vertical wavenumber spectra have amplitudes smaller than a saturated one. There is a tendency of increasing discrepancy with the theoretically saturated spectra towards higher wavenumbers. Steiner and Kirchengast (2000) observed dominant fluctuations occurring at wavelengths near 3 and $5 \mathrm{~km}$. But assuming a saturated spectrum, dominant fluctuations should have the largest wavelengths allowed by the methodology. It can be easily shown that for two profiles with the same value of $\bar{E}_{\mathrm{p}}$ but with different spectral contributions in the regions of disagreement with the theoretical slope, the resulting wave activity (mean wave energy) is different if the ratio between kinetic and potential energy changes with vertical wavenumber (direct proportion in the mid-frequency approximation).

So, to use $\bar{E}_{\mathrm{p}}$ theoretically correctly as a wave activity proxy, the interval of IGW wavelengths used in the computation should be bounded by the longest and shortest vertical wavelength where the vertical wavenumber power spectra density of disturbances has a slope similar to the theoretically predicted one. This would, however, substantially limit the spectral extent of GPS RO IGW analysis. In addition, Luna et al. (2013) showed that the uncertainty in potential energy derived from GPS RO is influenced more by the choice of integration limits (lower and upper boundary of the vertical region) and maximal and minimal vertical wavelength of disturbances allowed by the filter.

Another approach for quantifying the wave activity, as proposed by Ern et al. (2004), is to compute momentum flux (vertical flux of horizontal pseudo-momentum according to the naming convention by Bühler, 2014), which is a conserved quantity. This approach is theoretically consistent, but it is limited by introducing additional approximations such as a sinusoidal dominant wavelength in the mid-frequency range. The advantage of this method could be seen in the results of, e.g., Wright and Gille (2013), where the enhancement of significance of wave activity around the Himalayas could be related to the better representation of lee wave activity with smaller slope of the phase lines (higher ratio between kinetic and potential energy), whose activity would be underestimated using $E_{\mathrm{p}}$. On the other hand, another large mountain range, the Andes, is oriented perpendicular to the mean winds. Thus, there is a shift to non-hydrostatic waves in comparison to the lee waves from the Himalayas (Durran and Klemp, 2003). This makes the Andes better visible in the $\bar{E}_{\mathrm{p}}$ analyses due overestimation of IGW activity, although concurrently their amplitudes could have been smoothed using the ordinary GPS temperature data (Steiner and Kirchengast, 2000), which is not the case in our analysis. In this discussion, to show our point, for simplicity we avoid discussing the effect of observational geometry with respect to the wave orientation, which could otherwise be a leading source of differences between observed IGW activity especially when contrasting Himalayas and Andes.

In our analysis we compute monthly averages of occultations on a $3^{\circ} \times 3^{\circ}$ grid. The number of profiles does not exceed a few tens of profiles per month in one grid box. This is not sufficient to remove individual qualities of each profile power spectrum by averaging. It is also highly probable, as discussed above, that these individual qualities (e.g. a peak at larger vertical wavelengths) would remain dominant in the locations with, e.g., unchanged meteorological conditions in the analysed month, even if the ensemble were large enough. This all leads us to the conclusion that the wave activity could be underestimated (or overestimated) and regions, e.g., with prevailing inertia gravity waves could be masked when analysing the $\bar{E}_{\mathrm{p}}$ distributions. This could be the case near the northern and northeastern Pacific coast, where additional analysis using the characteristics based on the rate of change of density perturbations with height (gradient Richardson number and sigma) reveals wave fields close to instability as seen, e.g., in Fig. 7.

\subsection{Implications for the large-scale dynamics}

Smith (2003) argued that zonal asymmetries in gravity wave activity contribute to zonal asymmetries in mesospheric geopotential height and might also have an effect on the 3D transport in the mesosphere. Demirhan Bari et al. (2013), using the approach of the 3-D residual circulation proposed by Kinoshita et al. (2010), recently investigated the longitudinal variations in the time-mean transport by the BrewerDobson circulation. In Fig. 3 in their paper they showed that the mean January residual circulation at $60^{\circ} \mathrm{N}$ (northward boundary of our region of interest) penetrates to the lowest altitude (below $20 \mathrm{~km}$ ) around $140^{\circ} \mathrm{E}$ (the meridian crossing our region of interest). This is in line with our findings of robust and persistent breaking of IGWs starting at anomalous low levels in the region of interest. Also the distributions of atmospheric quantities indicate robust downwelling of tropical air masses (enhanced branch of Brewer-Dobson circulation) reaching deeper into the stratosphere in the region of interest than elsewhere.

To investigate this in detail, we are currently preparing a study analysing model runs of a middle atmospheric mechanistic model with means of 3-D EP (Eliassen-Palm) flux and residual circulation diagnostic formulated by Noda (2014). The study will focus mainly on the structure of dynamics and transport in the region of interest. Another issue that we would like to address is the causality of processes behind the specific dynamics in this region. In particular, we are interested in whether the specific IGW activity in autumn alone could be the reason for anomalously high temperatures and enhanced downwelling in winter. On the other hand, the complexity of the atmospheric system favours feedback mechanisms between waves and mean state, as the anomalous 
wave activity is probably a result of favourable meteorological conditions for IGW sources and propagation.

Another hypothetical importance of this region is the possibility that such a confined IGW breaking region creates planetary waves. This theoretical possibility was mentioned, e.g., by Smith (2003), who suggested that momentum forcing associated with breaking gravity waves that have been filtered by planetary-scale wind variations below acts to generate planetary waves in the middle and upper mesosphere. This is supported for example by the jet wave-1 pattern in Fig. 2 (again a question of causality). The sourcing of planetary waves by the region of interest could be exceptional through its low altitude (breaking starting already below $20 \mathrm{~km}$ altitude).

Thus, in a further paper, we shall investigate possible formation and propagation directions of planetary waves caused by such a localised IGW forcing in model simulations. Although preliminary results (not shown here) suggest that the poleward propagating mode is smaller than the equatorward propagating one, it can have influence on the polar vortex stability. It is up to further studies to analyse the connection between the interannual variation in strength of wave activity in the region of interest in the autumn or winter season and the SSW occurrence.

The equatorward propagating planetary wave modes created in November, as described by Ortland (1997), can play an important role in the stratosphere-troposphere exchange in the tropical region, where they break in easterly winds. Such a process is supported by results from Riese et al. (2014) indicating that the longitude of maximal passage of tropical air into the stratosphere in autumn corresponds to our region of interest. Furthermore, Škerlak et al. (2015) identified an area south/southeast of the region of interest to have maximum tropopause fold frequency (in Dec-Jan-Feb 19792012). Finally, Berthet et al. (2007) used back trajectories driven by large-scale analysed wind fields to investigate troposphere to stratosphere transport and found, particularly in autumn, a region of significant transport south of the region of interest.

Finally, our findings can also have implications for weather forecast and climate change. Horinouchi (2014) studied the synoptic variability of precipitation and moisture transport roughly in the same area as ours. This study concluded that from the dynamical point of view, it is arguably more meaningful to view the synoptic variability as initiated in the upper troposphere and to place the formation of surface quasistationary fronts as an aspect of this variability. For climate change and the debate about acceleration of BrewerDobson circulation it seems more and more clear that it is necessary to consider the Brewer-Dobson as longitudinally variable as shown by Demirhan Bari et al. (2013). This is supported by the presented results in the sense of the wave pumping hotspot and anomalous dynamics area suggestive of enhanced downwelling.

\section{Summary and conclusions}

Using the GPS RO density profiles, we analysed the IGW activity in an area of low annual cycle amplitude in the northeastern Pacific-eastern Asia coastal region. Enhanced IGW potential energy values were found uniquely in the lower stratosphere region in this area in October and November. Convective and dynamical instability indicators suggest robust wave breaking in this region starting at anomalously low levels, and this was detected also in spring.

Possible IGW sources were examined, analysis of prevailing surface winds and wind direction change revealed ideal conditions for sources and vertical propagation of orographic waves. Other sources contributing to the enhanced wave activity in this region are likely a convective activity connected with the Kuroshio current, Doppler shifting of vertically propagating waves and in situ wave generation in the upper troposphere-lower stratosphere (e.g. geostrophic adjustment). The latter mechanism can become a very interesting and unique source of IGWs during the episodes of merging jets.

The reasons why this particular IGW activity hotspot was not discovered before as well as why the specific dynamics of this region have not been pointed out are discussed. There are possible subjective reasons like the best visibility and uniqueness of this hotspot in autumn or motivated research based on previous assumption of the wave activity in this region on the one hand and possible objective physical mechanisms on the other hand. Those mechanisms can be separated into two groups that can influence each other: first, there are differences between our study and other studies that use GPS RO dry temperature data and there are differences with studies using different wave activity proxies.

The novel usage of GPS RO dry density data in this study belongs to the first group. The dry density data are not filtered by the hydrostatic balance and contain more information than the dry temperature data in the shorter vertical wavelength range. For the larger vertical wavelength region, the comparison is generally inconclusive because of the dominance of the background separation method effect (Šácha et al., 2014). By relating the density and temperature backgrounds with the hydrostatic assumption, we are currently preparing a further study to reveal the differences and their spatio-temporal variations in the whole analysed spectrum. The study should help to quantify the contributions of the noise and non-hydrostatic IGWs to the differences between usage of the dry density and temperature data.

In the second group of mechanisms, which can influence the comparability of our results with those of other studies, the inaccuracy of using mean potential energy of disturbances as a wave activity proxy is an important point. Its discussion is related not only to the region of interest, but also the possibility of underestimating/overestimating the wave activity depending on the dominant IGW modes using $\bar{E}_{\mathrm{p}}$ is important in a general sense. The possibility of underestimat- 
ing/overestimating the wave activity must be kept in mind when comparing $\bar{E}_{\mathrm{p}}$ fields with the distributions of pseudomomentum flux or of the wave breaking indicators employed additionally in our analysis. For example, the regions with prevailing inertia IGWs can be masked using $\bar{E}_{\mathrm{p}}$.

We have also discussed possible consequences of the region of interest on the middle atmospheric dynamics and transport (e.g. Brewer-Dobson circulation), linkage to the conditions in the troposphere and the necessity to consider the real geographical and seasonal distribution of IGWs together with 3-D residual circulation diagnostics to learn about its change in a changing climate.

\section{The Supplement related to this article is available online at doi:10.5194/acp-15-13097-2015-supplement.}

Acknowledgements. The authors would like to thank to the relevant working teams for the reanalysis data sets: MERRA (obtained from NASA, http://disc.sci.gsfc.nasa.gov/daac-bin/DataHoldings.pl) and JRA-55 (obtained from http://jra.kishou.go.jp/JRA-55/index_ en.html). The study was supported by the Charles University in Prague, Grant Agency project nos. 108313 and 1474314, and by the grant no. SVV267308 and by the program of Charles University PRVOUK no. 45 "Physics". This study was also partly supported by grant from the DAAD scholarship program.

Edited by: F.-J. Lübken

\section{References}

Alexander, S., Klekociuk, A., and Tsuda, T.: Gravity wave and orographic wave activity observed around the Antarctic and Arctic stratospheric vortices by the COSMIC GPS-RO satellite constellation, J. Geophys. Res.-Atmos., 114, D17103, doi:10.1029/2009JD011851, 2009.

Alexander, S. P., Tsuda, T., and Kawatani, Y.: COSMIC GPS Observations of Northern Hemisphere winter stratospheric gravity waves and comparisons with an atmospheric general circulation model, Geophys. Res. Lett., 35, L10808, doi:10.1029/2008GL033174, 2008.

Allen, S. J. and Vincent, R. A.: Gravity wave activity in the lower atmosphere: Seasonal and latitudinal variations, J. Geophys. Res.Atmos., 100, 1327-1350, 1995.

AAndrews, D. G., Holton, J. R., and Leovy, C. B.: Middle Atmosphere Dynamics, Academic Press, 489 pp., 1987.

Anthes, R. A., Bernhardt, P. A., Chen, Y., Cucurull, L., Dymond, K. F., Ector, D., Healy, S. B., Ho, S. P., Hunt, D. C., Kuo, Y. H., Liu, H., Manning, K., McCormick, C., Meehan, T. K., Randel, W. J., Rocken, C., Schreiner, W. S., Sokolovskiy, S. V., Syndergaard, S., Thompson, D. C., Trenberth, K. E., Wee, T. K., Yen, N. L., and Zeng, Z.: The COSMIC/Formosat-3 mission: Early results, B. Am. Meteorol. Soc., 89, 313-333, doi:10.1175/BAMS89-3-313, 2008.
Baumgaertner, A. and McDonald, A.: A gravity wave climatology for Antarctica compiled from Challenging Minisatellite Payload/Global Positioning System (CHAMP/GPS) radio occultations, J. Geophys. Res.-Atmos., 112, D05103, doi:10.1029/2006JD007504, 2007.

Berthet, G., Esler, J. G., and Haynes, P. H.: A Lagrangian perspective of the tropopause and the ventilation of the lowermost stratosphere, J. Geophys. Res., 112, D18102, doi:10.1029/2006JD008295, 2007.

Bühler, O.: Waves and mean flows, Cambridge University Press, 2014.

CCMVal, S.: SPARC Report on the Evaluation of ChemistryClimate Models, edited by: Eyring, V., Shepherd, T. G., and Waugh, D. W., Tech. rep., SPARC Report, 2010.

De la Torre, A., Schmidt, T., and Wickert, J.: A global analysis of wave potential energy in the lower stratosphere derived from 5 years of GPS radio occultation data with CHAMP, Geophys. Res. Lett., 33, L24809, doi:10.1029/2006GL027696, 2006.

Demirhan Bari, D., Gabriel, A., Körnich, H., and Peters, D. W. H.: The effect of zonal asymmetries in the Brewer-Dobson circulation on ozone and water vapor distributions in the northern middle atmosphere, J. Geophys. Res.-Atmos., 118, 3447-3466, doi:10.1029/2012JD017709, 2013.

Durran, D. R. and Klemp, J. B.: The Effects of Moisture on Trapped Mountain Lee Waves, J. Atmos. Sci., 39, 2490-2506 doi:10.1175/1520-0469(1982)039<2490:TEOMOT>2.0.CO;2, 2003.

Ebita, A., Kobayashi, S., Ota, Y., Moriya, M., Kumabe, R., Onogi, K., Harada, Y., Yasui, S., Miyaoka, K., Takahashi, K., Kamahori, H., Kobayashi, C., Endo, H., Soma, M., Oikawa, Y., and Ishimizu, T.: The Japanese 55-year Reanalysis (JRA-55): an interim report, SOLA, 7, 149-152, 2011.

Ern, M. and Preusse, P.: Gravity wave momentum flux spectra observed from satellite in the summertime subtropics: Implications for global modeling, Geophys. Res. Lett., 39, L15810, doi:10.1029/2012GL052659, 2012.

Ern, M., Preusse, P., Alexander, M. J., and Warner, C. D.: Absolute values of gravity wave momentum flux derived from satellite data, J. Geophys. Res.-Atmos., 109, D20103, doi:10.1029/2004JD004752, 2004.

Ern, M., Preusse, P., Gille, J., Hepplewhite, C., Mlynczak, M., Russell, J., and Riese, M.: Implications for atmospheric dynamics derived from global observations of gravity wave momentum flux in stratosphere and mesosphere, J. Geophys. Res.-Atmos., 116, D19107, doi:10.1029/2011JD015821, 2011.

Ern, M., Arras, C., Faber, A., and Fröhlich, K.: Observations and Ray Tracing of Gravity Waves: Implications for Global Modeling, Climate and Weather of the Sun-Earth System (CAWSES), pp. 383-408, doi:10.1007/978-94-007-4348-9, 2013.

Ern, M., Ploeger, F., Preusse, P., Gille, J. C., Gray, L. J., Kalisch, S., Mlynczak, M. G., Russell, J. M., and Riese, M.: Interaction of gravity waves with the QBO: A satellite perspective, J. Geophys. Res.-Atmos., 119, 2329-2355, doi:10.1002/2013JD020731, 2014.

Faber, A., Llamedo, P., Schmidt, T., de la Torre, A., and Wickert, J.: On the determination of gravity wave momentum flux from GPS radio occultation data, Atmos. Meas. Tech., 6, 3169-3180, doi:10.5194/amt-6-3169-2013, 2013. 
Foelsche, U., Borsche, M., and Steiner, A.: Observing upper troposphere-lower stratosphere climate with radio occultation data from the CHAMP satellite, Clim. Dynam., 31, 49-65, doi:10.1007/s00382-007-0337-7, 2008.

Fritts, D. C.: Gravity wave saturation in the middle atmosphere: A review of theory and observations, Rev. Geophys., 22, 275-308, doi:10.1029/RG022i003p00275, 1984.

Fritts, D. C. and Alexander, M. J.: Gravity wave dynamics and effects in the middle atmosphere, Rev. Geophys., 41, 1003, doi:10.1029/2001RG000106, 2003.

Garcia, R. R. and Randel, W. J.: Acceleration of the Brewer-Dobson circulation due to increases in greenhouse gases, J. Atmos. Sci., 65, 2731-2739, 2008.

Hardiman, S. C. and Haynes, P. H.: Dynamical sensitivity of the stratospheric circulation and downward influence of upper level perturbations, J. Geophys. Res., 113, D23103, doi:10.1029/2008JD010168, 2008.

Hartley, D., Villarin, J., Black, R., and Davis, C.: A new perspective on the dynamical link between the stratosphere and troposphere, Nature, 8311, 1996-1999, 1998.

Haynes, P.: Stratospheric Dynamics, Annu. Rev. Fluid Mech., 37, 263-293, doi:10.1146/annurev.fluid.37.061903.175710, 2005.

Haynes, P., McIntyre, M., Shepherd, T., Marks, C., and Shine, K. P.: On the "downward control" of extratropical diabatic circulations by eddy-induced mean zonal forces, J. Atmos. Sci., 48, 651-678, 1991.

Hei, H., Tsuda, T., and Hirooka, T.: Characteristics of atmospheric gravity wave activity in the polar regions revealed by GPS radio occultation data with CHAMP, J. Geophys. Res.-Atmos., 113, D04107, doi:10.1029/2007JD008938, 2008.

Hertzog, A., Alexander, M. J., and Plougonven, R.: On the intermittency of gravity wave momentum flux in the stratosphere, J. Atmos. Sci., 69, 3433-3448, 2012.

Hirota, I. and Niki, T.: A statistical study of inertia-gravity waves in the middle atmosphere, J. Meteorol. Soc. Jpn., 63, 1055-1066, 1985.

Horinouchi, T.: Influence of Upper Tropospheric Disturbances on the Synoptic Variability of Precipitation and Moisture Transport over Summertime East Asia and the Northwestern Pacific, J. Meteorol. Soc. Jpn. Ser. II, 92, 519-541, doi:10.2151/jmsj.2014602, 2014.

Horinouchi, T. and Tsuda, T.: Spatial structures and statistics of atmospheric gravity waves derived using a heuristic vertical cross-section extraction from COSMIC GPS radio occultation data, J. Geophys. Res.-Atmos., 114, D16110, doi:10.1029/2008JD011068, 2009.

Jia, J. Y., Preusse, P., Ern, M., Chun, H.-Y., Gille, J. C., Eckermann, S. D., and Riese, M.: Sea surface temperature as a proxy for convective gravity wave excitation: a study based on global gravity wave observations in the middle atmosphere, Ann. Geophys., 32, 1373-1394, doi:10.5194/angeo-32-1373-2014, 2014.

Jiang, J. H., Eckermann, S. D., Wu, D. L., and Ma, J.: A search for mountain waves in MLS stratospheric limb radiances from the winter Northern Hemisphere: Data analysis and global mountain wave modeling, J. Geophys. Res.-Atmos., 109, D03107, doi:10.1029/2003JD003974, 2004.

John, S. R. and Kumar, K. K.: TIMED/SABER observations of global gravity wave climatology and their interannual variabil- ity from stratosphere to mesosphere lower thermosphere, Clim. Dynam., 39, 1489-1505, 2012.

Kinoshita, T., Tomikawa, Y., and Sato, K.: On the ThreeDimensional Residual Mean Circulation and Wave Activity Flux of the Primitive Equations, J. Meteorol. Soc. Jpn., 88, 373-394, doi:10.2151/jmsj.2010-307, 2010.

Kozubek, M., Krizan, P., and Lastovicka, J.: Northern Hemisphere stratospheric winds in higher midlatitudes: longitudinal distribution and long-term trends, Atmos. Chem. Phys., 15, 2203-2213, doi:10.5194/acp-15-2203-2015, 2015.

Kuchař, A., Šácha, P., Miksovsky, J., and Pišoft, P.: The 11-year solar cycle in current reanalyses: a (non)linear attribution study of the middle atmosphere, Atmos. Chem. Phys., 15, 6879-6895, doi:10.5194/acp-15-6879-2015, 2015.

Lange, M. and Jacobi, C.: Analysis of gravity waves from radio occultation measurements, in: First CHAMP mission results for gravity, magnetic and atmospheric studies, pp. 479-484, Springer, 2003.

Luna, D., Alexander, P., and de la Torre, A.: Evaluation of uncertainty in gravity wave potential energy calculations through GPS radio occultation measurements, Adv. Space Res., 52, 879-882, doi:10.1016/j.asr.2013.05.015, 2013.

Marquardt, C. and Healy, S.: Measurement Noise and Stratospheric Gravity Wave Characteristics Obtained from GPS Occultation Data, J. Meteorol. Soc. Jpn., 83, 417-428, doi:10.2151/jmsj.83.417, 2005.

Marshall, A. G. and Scaife, A. A.: Impact of the QBO on surface winter climate, J. Geophys. Res.-Atmos., 114, D18110, doi:10.1029/2009JD011737, 2009.

McDonald, A. J., Tan, B., and Chu, X.: Role of gravity waves in the spatial and temporal variability of stratospheric temperature measured by COSMIC/FORMOSAT-3 and Rayleigh lidar observations, J. Geophys. Res., 115, D19128, doi:10.1029/2009JD013658, 2010.

Mohri, K.: On the fields of wind and temperature over Japan and adjacent waters during winter of 1950-1951, Tellus, 5, 340-358, 1953.

Noda, A.: Generalized Transformed Eulerian Mean (GTEM) Description for Boussinesq Fluids, J. Meteorol. Soc. Jpn. Ser. II, 92, 411-431, doi:10.2151/jmsj.2014-501, 2014.

Oberheide, J.: Geostrophic wind fields in the stratosphere and mesosphere from satellite data, J. Geophys. Res., 107, 8175, doi:10.1029/2001JD000655, 2002.

Ortland, D. A.: Rossby wave propagation into the tropical stratosphere observed by the High Resolution Doppler Imager, Geophys. Res. Lett., 24, 1999-2002, 1997.

Percival, D. B. and Walden, A. T.: Wavelet methods for time series analysis, Vol. 4, Cambridge University Press, 2006.

Pišoft, P., Mikšovsk, J., and Žák, M.: An analysis of the spatial distribution of approximate 8 years periodicity in NCEP/NCAR and ERA-40 temperature fields, Eur. Phys. J.-Spec. Top, 174, 147155, 2009.

Pisoft, P., Miksovsky, J., Kalvova, J., Raidl, A., and Zak, M.: Areal analysis of oscillations in 500-hPa temperature field: a pseudo2D wavelet transform approach, Int. J. Climatol., 31, 1545-1553, 2011.

Pišoft, P., Holtanova, E., Huszar, P., Kalvova, J., Miksovsky, J., Raidl, A., Zemankova, K., and Zak, M.: Manifestation of reana- 
lyzed QBO and SSC signals, Theor. Appl. Climatol., 112, 637646, doi:10.1007/s00704-012-0752-5, 2013.

Plougonven, R. and Zhang, F.: Internal gravity waves from atmospheric jets and fronts, Rev. Geophys., 52, 33-76, doi:10.1002/2012RG000419, 2014.

Preusse, P. and Ern, M.: Indication of convectively generated gravity waves observed by CLAES, Adv. Space Res., 35, 1987-1991, 2005.

Preusse, P., Eidmann, G., Eckermann, S. D., Schaeler, B., Spang, R., and Offermann, D.: Indications of convectively generated gravity waves in crista temperatures, Adv. Space Res., 27, 1653-1658, doi:10.1016/S0273-1177(01)00231-9, 2001.

Ratnam, M. V., Tetzlaff, G., and Jacobi, C.: Global and seasonal variations of stratospheric gravity wave activity deduced from the CHAMP/GPS satellite, J. Atmos. Sci., 61, 1610-1620, 2004.

Rienecker, M. M., Suarez, M. J., Gelaro, R., Todling, R., Bacmeister, J., Liu, E., Bosilovich, M. G., Schubert, S. D., Takacs, L., Kim, G. K., Bloom, S., Chen, J., Collins, D., Conaty, A., da Silva, A., Gu, W., Joiner, J., Koster, R. D., Lucchesi, R., Molod, A., Owens, T., Pawson, S., Pegion, P., Redder, C. R., Reichle, R., Robertson, F. R., Ruddick, A. G., Sienkiewicz, M., and Woollen, J. MERRA: NASA's modern-era retrospective analysis for research and applications, J. Climate, 24, 3624-3648, 2011.

Riese, M., Oelhaf, H., Preusse, P., Blank, J., Ern, M., Friedl-Vallon, F., Fischer, H., Guggenmoser, T., Höpfner, M., Hoor, P., Kaufmann, M., Orphal, J., Plöger, F., Spang, R., Suminska-Ebersoldt, O., Ungermann, J., Vogel, B., and Woiwode, W.: Gimballed Limb Observer for Radiance Imaging of the Atmosphere (GLORIA) scientific objectives, Atmos. Meas. Tech., 7, 1915-1928, doi:10.5194/amt-7-1915-2014, 2014.

Šácha, P., Foelsche, U., and Pišoft, P.: Analysis of internal gravity waves with GPS RO density profiles, Atmos. Meas. Tech., 7, 4123-4132, doi:10.5194/amt-7-4123-2014, 2014.

Sato, K.: A statistical study of the structure, saturation and sources of inertio-gravity waves in the lower stratosphere observed with the $\{\mathrm{MU}\}$ radar, J. Atmos. Terr. Phy., 56, 755-774, doi:10.1016/0021-9169(94)90131-7, 1994.

Scherllin-Pirscher, B., Steiner, A. K., and Kirchengast, G.: Deriving dynamics from GPS radio occultation: Three-dimensional wind fields for monitoring the climate, Geophys. Res. Lett., 41, 73677374, doi:10.1002/2014GL061524, 2014.

Schmidt, T., de la Torre, A., and Wickert, J.: Global gravity wave activity in the tropopause region from CHAMP radio occultation data, Geophys. Res. Lett., 35, L16807, doi:10.1029/2008GL034986, 2008.

Senft, D. C. and Gardner, C. S.: Seasonal variability of gravity wave activity and spectra in the mesopause region at Urbana, J. Geophys. Res., 96, 17229, doi:10.1029/91JD01662, 1991.

Škerlak, B., Sprenger, M., Pfahl, S., Tyrlis, E., and Wernli, H.: Tropopause folds in ERA-Interim: Global climatology and relation to extreme weather events, J. Geophys. Res.-Atmos., 120, 4860-4877, doi:10.1002/2014JD022787, 2015.

Smith, A. K.: The origin of stationary planetary waves in the upper mesosphere, J. Atmos. Sci., 60, 3033-3041, 2003.

Smith, S. A., Fritts, D. C., and Vanzandt, T. E.: Evidence for a saturated spectrum of atmospheric gravity waves, J. Atmos. Sci., 44, 1404-1410, 1987.
Steiner, A. K. and Kirchengast, G.: Gravity Wave Spectra from GPS/MET Occultation Observations, J. Atmos. Ocean. Tech., 17, 495-503, doi:10.1175/15200426(2000)017<0495:GWSFGM>2.0.CO;2, 2000.

Sutherland, B. R.: Internal gravity waves, Cambridge University Press, 2010.

Torrence, C. and Compo, G. P.: A practical guide to wavelet analysis, B. Am. Meteorol. Soc., 79, 61-78, 1998.

Trinh, Q. T., Kalisch, S., Preusse, P., Chun, H.-Y., Eckermann, S. D., Ern, M., and Riese, M.: A comprehensive observational filter for satellite infrared limb sounding of gravity waves, Atmos. Meas. Tech., 8, 1491-1517, doi:10.5194/amt-8-1491-2015, 2015.

Tsuda, T., Murayama, Y., Nakamura, T., Vincent, R., A. H. Manson, Meek, C., and Wilson, R.: Variations of the gravity wave characteristics with height, season and latitude revealed by comparative observations, J. Atmos. Terr. Phys., 56, 555-568, doi:10.1016/0021-9169(94)90097-3, 1994.

Tsuda, T., Nishida, M., Rocken, C., and Ware, R. H.: A global morphology of gravity wave activity in the stratosphere revealed by the GPS occultation data (GPS/MET), J. Geophys. Res.-Atmos., 105, 7257-7273, 2000.

VanZandt, T. E.: A model for gravity wave spectra observed by Doppler sounding systems, Radio Sci., 20, 1323-1330, 1985.

Verkhoglyadova, O. P., Leroy, S. S., and Ao, C. O.: Estimation of Winds from GPS Radio Occultations, J. Atmos. Ocean. Tech., 31, 2451-2461, doi:10.1175/JTECH-D-14-00061.1, 2014.

Wang, L. and Alexander, M.: Global estimates of gravity wave parameters from GPS radio occultation temperature data, J. Geophys. Res.-Atmos., 115, D21122, doi:10.1029/2010JD013860, 2010.

Wang, L. and Alexander, M. J.: Gravity wave activity during stratospheric sudden warmings in the 2007-2008 Northern Hemisphere winter, J. Geophys. Res.-Atmos., 114, D18108, doi:10.1029/2009JD011867, 2009.

Wilson, R., Chanin, M., and Hauchecorne, A.: Gravity waves in the middle atmosphere observed by Rayleigh lidar: 2. Climatology, J. Geophys. Res.-Atmos., 96, 5169-5183, 1991.

Wright, C. and Gille, J.: Detecting overlapping gravity waves using the S-Transform, Geophys. Res. Lett., 40, 1850-1855, doi:10.1002/grl.50378, 2013.

Wright, C. J., Rivas, M. B., and Gille, J. C.: Intercomparisons of HIRDLS, COSMIC and SABER for the detection of stratospheric gravity waves, Atmos. Meas. Tech., 4, 1581-1591, doi:10.5194/amt-4-1581-2011, 2011.

Wright, C. J., Osprey, S. M., and Gille, J. C.: Global observations of gravity wave intermittency and its impact on the observed momentum flux morphology, J. Geophys. Res.-Atmos., 118, 1098010993, doi:10.1002/jgrd.50869, 2013.

Zhang, Y., Xiong, J., Liu, L., and Wan, W.: A global morphology of gravity wave activity in the stratosphere revealed by the 8-year SABER/TIMED data, J. Geophys. Res.-Atmos., 117, D21101, doi:10.1029/2012JD017676, 2012. 